\title{
Decision Support Systems Classification in Industry
}

\author{
Musbah J. Aqel ${ }^{1}$, Omar A. Nakshabandi ${ }^{2}$, Ayodeji Adeniyi ${ }^{3}$ \\ ${ }^{1,2,3}$ Cyprus International UniversitymLefkosa, North Cyprus
}

\section{Article Info}

Received Jan 9, 2019

\begin{abstract}
This research has presented a discussion of related literature on decision support systems (DSS) and its role in production systems. The first part of the research presents DSS and how this has evolved until 2010. The next part of the research provides a discussion of the decision making process and the data mining phases as these relate to DSS. The last part of the research presents further discussion of DSS and various perspectives on the criteria that could be used for DSS. The criteria in the classification of DSS includes the following: user relationship; orientation; scope of use; type and frequency of decision making; mode of assistance; focus area; objective; capacity; degree of guidance; and, degree of non-procedurality. The research also included a discussion of industry 4.0, which is known as the fourth revolution in the industry.
\end{abstract}

\section{Corresponding Author:}

FirstAuthor,

Musbah J. Aqel

Cyprus International University

Lefkosa, North Cyprus

maqel@ciu.edu.tr

\section{Introduction}

There has been a strong focus and need for production firms to enable and utilize systems that support production processes and which align with the dynamic business environment. Traditionally, the systems that have been utilized for internal processing of data and information have largely been limited to the execution of transactional support. Increased business requirements have brought on the requirements for more powerful, complex and comprehensive systems that can manage automated data collection and support continued innovations in various aspects of production systems including Enterprise Resource Planning (ERP) and Production Execution Systems. Recent developments and advancement in the use of Business Intelligence and Big Data have led to the introduction of new applications and methods to expand capabilities of already existing decision support systems (DSS), the focus of this research. DSS is utilized in the facilitation of organizational activities and involves the use of varied types of types of data: structured; semi-structured; and, unstructured [7]. A key advantage in the use of DSS is the capability in mining data effectively from a source to build the data into a structured form so that it can then be used to support decision making of organizations fulfilling an objective of DSS in the minimization of errors in production processes. Effectively, DSS is considered as one of the development of information technology systems that have the capabilities to improve and support organizations in decision making processes.

This has a long history with the development of computers and technology providing increased capabilities with the evolution of DSS from continued research and development efforts. The result is that, over the years, DSS has transformed from initially being a decision support system for individuals to evolving one that is used for groups. This has further advanced to become intelligent decision support systems which provide support for executive information systems with DSS now utilized across different capabilities including business analytics, negotiation support systems, business intelligence, and data warehousing. In recent times, there has been increased use of DSS for business 
intelligence as technology has evolved and this utilization has become more paramount with increased competition in the market [7].

\section{$\underline{\text { DSS Evolution }}$}

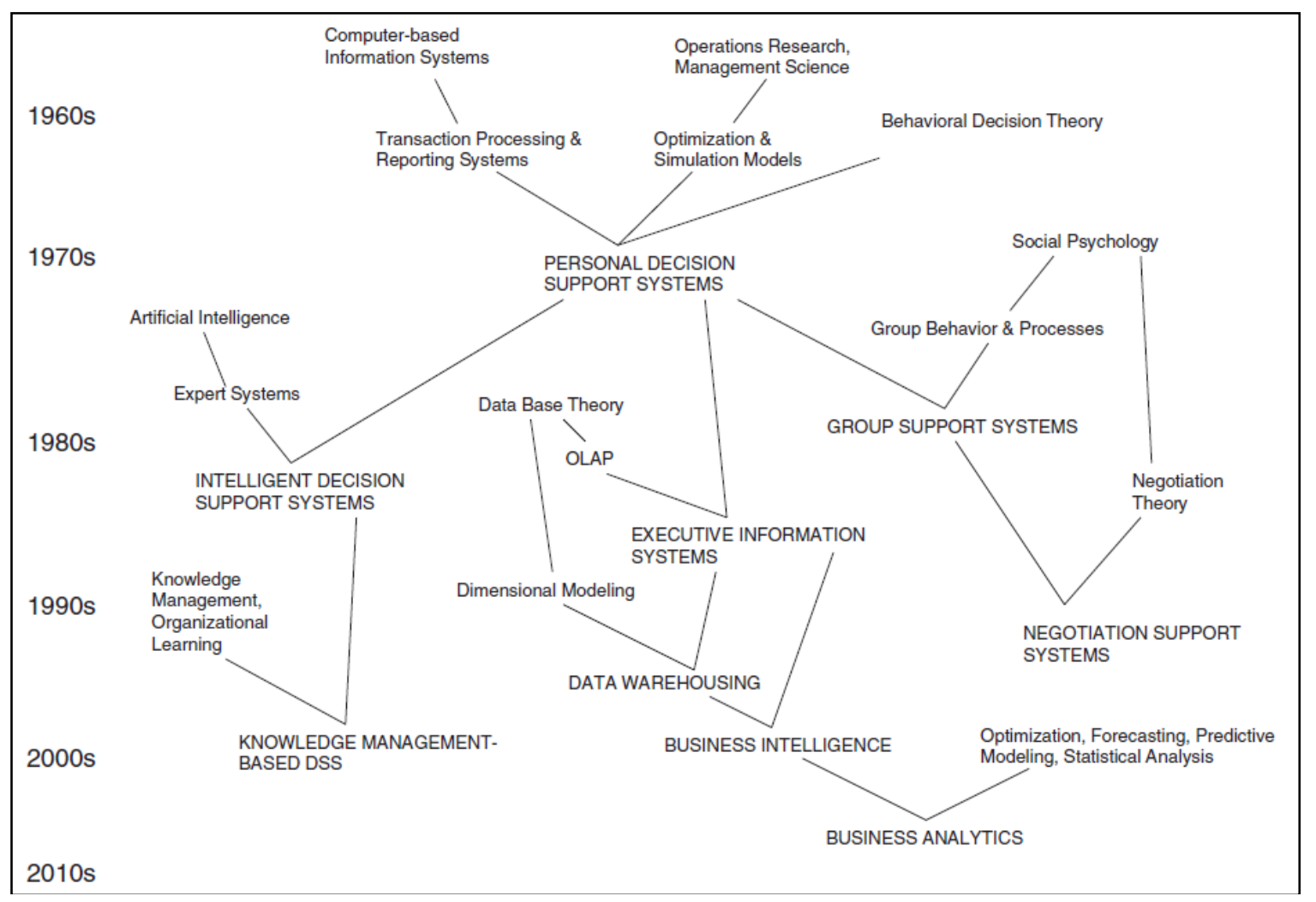

Figure 1: DSS Field Genealogy. Adapted from Arnott \&Pervan (2016)

\section{Definitions of Decision Support Systems (DSS)}

Given the research available on DSS, various definitions have been provided by scholars to present the differing perspectives on DSS. According to Trianni et al [29], DSS involves computer systems that address issues that could be a combination of structured and unstructured components.

In 1960, Simon presented DSS as involving decision problems that were continuous and had programmed (properly structured and simple problems) and un-programmed (novel, unstructured and complex problems) components [24]. Samuel et al. [26] provide another perspective and present DSS as how computers are involved in the decision making processes as part of an overall system for organizations. For structures and activities, DSS provides the requirements related to the unique design that presents support to the human cognitive processes and complements an approach that leverages the use of computers and technology to aid managers and decision makers.

The Process of Decision making in an organization

Simon et al and Fielder et al. [8] highlights that decision making processes involve activities that lead to the identification of potential solutions and alternatives to be considered to address unstructured problems. It has been argued that DSS does not only relate to providing and defining the alternatives but also generating and identifying the alternative thatwould best align with the organizational goals and objectives. There are different steps that are involved in the process of decision making in organizations.

Problem Identification: This is considered as the initial step in the process of decision making as this is where the issue defined, the stakeholders are identified, and the decision makers for the organization are acknowledged.

The process for decision making is considered as following a top-down approach with provisions and steps in the process for returning to earlier stages of the hierarchy [14]. 


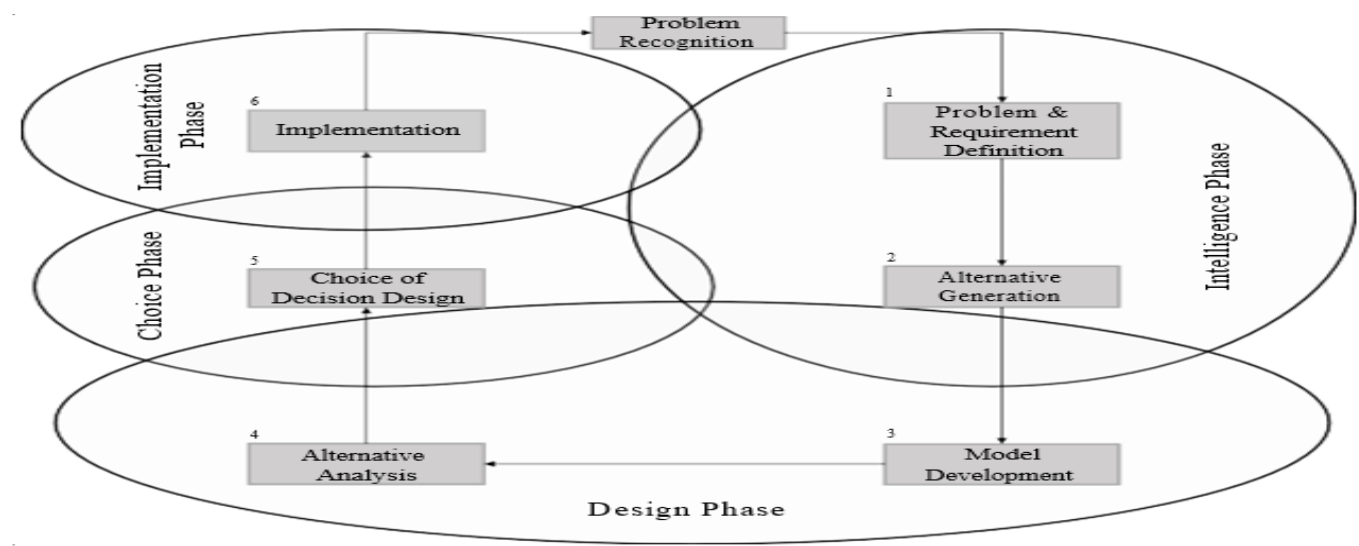

Figure 2: Process of Decision-making

\section{The Decision Making Process}

Problem Requirement Specification and Generation (Phases I and 2): As part of the process of decision making, the initial step is in defining the problem properly as soon as a problem has been identified [14].

The objective of phase 1 in the decision making process is in documenting the issue and defining the requirements that are important to be met before the objectives are clearly articulated. The action to define the requirements to be addressed highlights the aspects of the solutions that will address the problems [6]. Phase 2: The next phase is in generating alternatives that provides individuals and the organizations with options to consider in minimizing the ambiguity existing in the decision making process. An important factor to consider is that the options generated need to align with the stated requirements in solving the problems. This phase of the decision making process is also referred to as the "intelligence gathering phase" which is a step in the identification of problems and generation of alternatives. The outcomes that result from this stage would be considered as authoritative in context and can be used in forming a decision statement.

Development of Model (Phases 3): The next step after generating alternatives for solutions and choosing the option that would seem to be aligned with organizational objectives and would be the best fit is the development of a model. In the decision making process, the models are utilized $\mathrm{n}$ the analysis of the generated alternatives. In the analysis of the alternatives, a measurement needs to be established to ensure the objective assessment of the effectiveness of the alternative chosen. The best model would be one that can analyze the alternatives provided in a quick manner and in alignment with organizational objectives[28].

Alternative Analysis (Phase 4): Following the development of the model, the next stage in the decision making process is the analysis of the options identified and this would be a path that could lead to concluding the best option to take based on the assessment of the options against the defined measures with the use of supporting tools for decision making. There are many decision making process support tools such as the Analytical Hierarchy Process (AHP), Multi-Attribute Utility Theory Analysis (MAUT), Pros and Cons Analysis and the Kepner-Tregoe Decision Analysis (KT) [19]. In recent years, there have been studies focused on the evaluation of the appropriateness of the decision making support tools, the advantages and disadvantages of each, and the applicability of the tools in situations in which the decisions have been changed following the use of specific methods [30]. Finally, the solution identified must be assessed in terms of the extent in which the initial problem identified is addressed. This part of the process is known as the "Design phase" with the different solution options being established and the organizational objectives are integrated into the models.

Decision Choice Design (Phase 5): In this phase, the actual decision chosen from the set of alternative solutions generated during the design phase is prepared for execution as part of the "Implementation Phase"

Implementation (Phase 6): In this phase, the option identified for execution is implemented. The key consideration is that the option chosen as the solution should meet all the defined requirements and address the stated organizational objectives within context of the decision making process.

\section{Decision Support System Architecture}

There are many elements that comprise the DSS. The first element is a software component that is referred to as the Database Management System (DBMS) and this provides the handling of the access to the data, the manipulation and management of the data that is stored internally in the database and data that is external to the database [1]. The second element is the Model Management System (MBMS) which uses different mathematical models in the analysis of complex data for the presentation and engagement with the user via the interface utilized by the user [5]. 


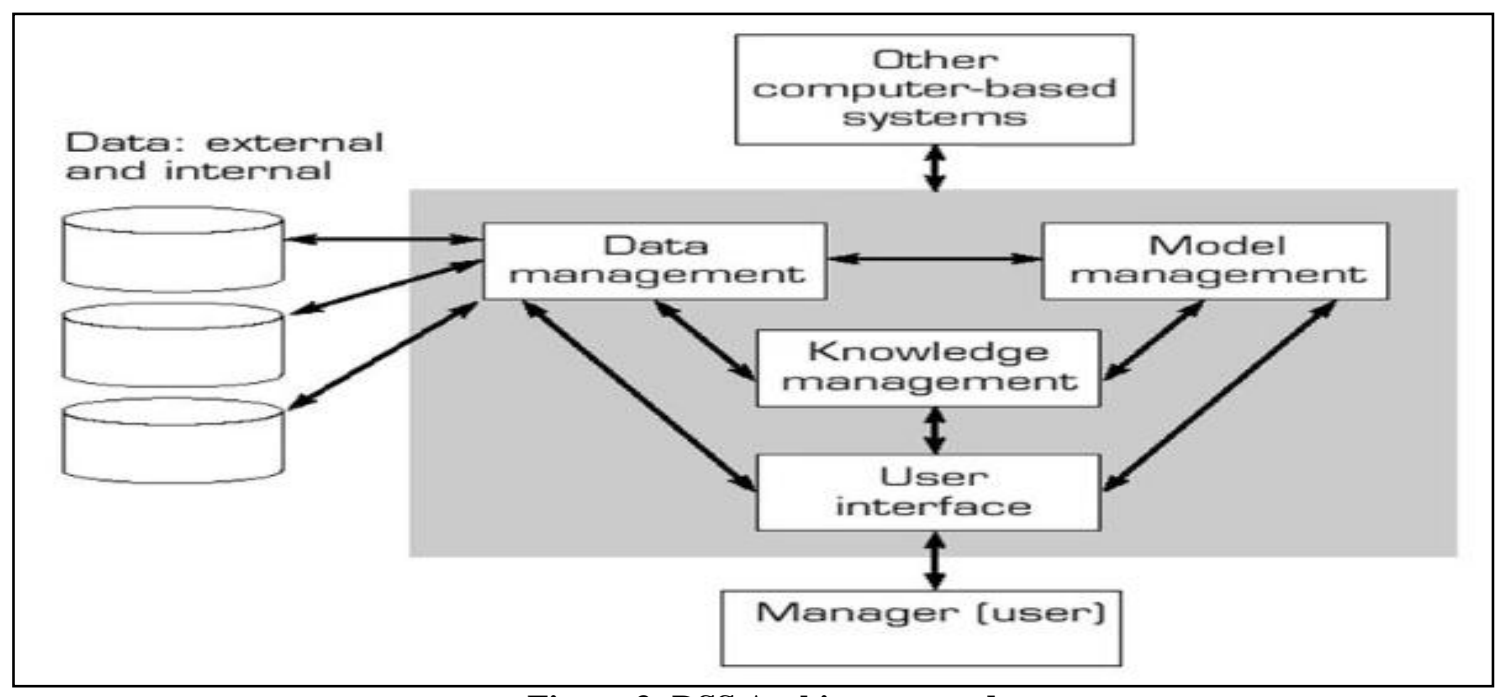

Figure 3: DSS Architecture and components

\section{Data Mining Process}

Data cleaning

Data integration

Data selection

Data transformation

Data mining

Evaluation

Deployment of knowledge

Data cleaning: This is the initial step in the process and is designed to filter out the errors in the data including incoherent and consistent data to prepare the data for integration.

Data Integration: The next step in the process and with the data coming from different sources, this phase provides the integration of the data across the various sources [3].

Data Selection: This phase involves the selection of the relevant and useful data that will be utilized for the analysis.

Data Transformation: With the data being collated in different forms, this step involves the conversion of the data into the relevant and appropriate form for the data to be ready for the data mining step.

Data Mining: In this step of the process, the data mining phase is executed such that the data leads to information that is valuable in the discovery of knowledge.

Evaluation: The next step is the evaluation of the data against the data mining objectives with the view that the outcomes from the mined data needing to fulfill the data mining objectives that were defined and set up in the initial stages of the process.

Deployment of Knowledge: In this last step, the key consideration is the use of the results of the data mined so that knowledge is developed and communicated.

\section{Taxonomy of DSS}

Similar to how several definitions of DSS have been presented, there is no agreement on the standard taxonomy and classification in the use of DSS. Various authors have proposed a set of classification considerations in order to have a classification of DSS that can be agreed on even if based on different parameters. For this research, a set of classifications is presented based on the literature reviewed for DSS:

User Relationship: Passive, Active and Cooperative [11].

Mode of Assistance: Data Driven, Knowledge Driven, Model Driven, Communication Driven, Document Driven DSS and Web Based DSS [21].

Scope of Use: Enterprise-wide DSS and Desktop-wide DSS [17].

Orientation: Text-oriented DSS, Database-oriented DSS, Rule-oriented DSS, Solver-oriented DSS, Spreadsheet-oriented DSS, Compound-oriented DSS) [12].

Focus Area: Data Focus, Model Focus and Knowledge Focus[12].

Type and Frequency of Decision Making (Institutional DSS and Ad-hoc DSS)

DSS Classification based on Capacity (Individual and Group DSS)

DSS Classification based on Objective (Custom and Ready-made DSS)

DSS Classification based on degree of guidance (Directed and Non-directed DSS)

DSS Classification based on degree of non-Procedurality(Procedural and Non Procedural DSS) 


\section{Decision Support Systems}

The decision support systems can have a classification across different types based on multi-criteria given earlier from literature reviewed.

\section{Decision Support Systems Classification based on User Relationship}

According to Garg [9], there are DSS types; active DSS; passive DSS; and, cooperative DSS. Garg [9] provides an overview for each of the DSS types. An active DSS has the capability to build decision guidelines that are developed to support the decision making for solutions to issues. A passive DSS does not build decision guidelines but only provides support to the decision making process. The cooperative DSS provides the decision maker the ability to execute changes and modifications to the suggestions presented by the system and to send these back to the system for another round of evaluation. The system enhances and redefines the input before this is then sent back to the user. This process is executed again until the decision maker accepts an adequate solution.

DSS has also been considered as a key component of an information system where data and information are retrieved for the transaction processing system during the interaction with other elements of the information system with the main objective of providing supporting to the decision making of managers in organizations [22].

\section{DSS Classification based on Mode of Assistance}

\section{Data-driven Decision Support System (DSS)}

Data-driven DSS involves the access and manipulation of data that is structured and which includes time series functionality handling to fulfill the external and internal data requirements of organizations as the data is managed [31]. There are clear distinctions in the functionality of data in data-driven DSS. The file systems can easily be utilized through queries and retrieved through tools that have a lower functional level. The more comprehensive systems that are utilized by senior management such as the Executive Information Systems (EIS) allow the manipulation of data which are supported with tools that have been automated and have functionality that could be considered more comprehensive. Other applications of data-driven decision support systems arebusiness intelligence systems and Online Analytical Processing (OLAP) systems which provide the most significant support level for organizational decision makers [32].

The BI systems provide support to decision making in organizations through the use of technology which enable the access to the data and related analytics, and their presentation. More simply, the BI systems aid decision makers in formulating decisions when these are initiated, manipulating the data as needed, and analyzing the data and information that are in the databases [22]. A key aim of the use of BI and Analytic Systems is to enhance the role of data and information in supporting decisions primarily through improved processing of data. The decisions are supported as the data-driven DSS enables the management through a significant volume of data which are typically complemented by the excellent level of quality of the primary data. The extent of success of DSS in this context is based on the ability of the systems to have access to error-free, well-structured and organized data and information which means that a deviation from these parameters may lead to an inefficient DSS [22].

\section{Model-driven Decision Support System (DSS)}

Power et al. [22] argues that a model-driven DSS leverages different elements of financial models, optimization models, and simulation models which are all integrated in the decision making support processes. A model-driven decision support systems is a specially designed model patterned after specific parameters and features defined by the users to include the property of support to decision making process through the analysis of given situations. The model-driven decision support systems does not require a large demand for data as there is minimal need for databases, if any with data and information only needed for specific data analysis requirements. The key feature in the design of a model-driven DSS is the integration of single or multiple qualitative models as part of the systems to provide increased efficiency in the analysis of solutions. The model-driven DSS leverages analytical tools and these are based on mathematical models that give the model-driven DSS the initial functional features which are required and utilized in the model-driven DSS applications. Typically, the mathematical models are designed as part of spreadsheets. In designing more complex models that are geared to provide decision making support, the model utilizes optimization programs and mathematical applications. An underlying feature of a model-drive DSS is that this would typically represent the interpretation of realism.

Recently, the model-driven DSS has been utilized in expanded levels with a set of different models providing support for decision making across various parts of the supply chain including the manufacturing, planning and scheduling processes together with the logistics planning and management [22]. In addition, the model-driven DSS is used in various aspects of supply chain management (SCM) with the decisions supported by simulation models including the Monte Carlo simulation and other similar imitation methods such as agent and multi agent simulation, and visual simulation models [22].

\section{Communication-driven Decision Support System (DSS)}

Typically, a communication-driven DSS relies on a network fusion and electronic methods to integrate core decision makers in given situations by consolidating the decision makers into one environment which has all the data, information and resources that are needed for decision making. These are shared and made available to the decision makers thereby enabling increased collaboration and communication among the group to facilitate improved decision making. This model is now formally referred to as Group Decision Support System (GDSS) following many years in which this model 
was initially referred to as group decision making (GDM), a sub category of in the subject of decision making. The GDSS involves many tools that are relevant for problem solving and problem structuring including planning and modelling tools.

A different example of a communication-driven DSS is the Collaborative DSS (CDSS) which has elements of computer systems that enable engagement between decision makers with the increased interaction allowing the group to work together in defining solutions for the problems, even when these are novel problems or unstructured issues [22]. The collaborative DSS can be executed through a hybrid of IT equipment that already integrates modeling analysis tools thereby providing a platform that is easy for the users to leverage to identify solutions and execute decisions [1].

\section{Document-driven Decision Support System (DSS)}

Previously, as organizations continued to operate and expand, document management became an important feature for organizations to manage and store relevant documents and other materials such as photos and images, and audio and video files. These resources including communications correspondences were increasingly stored electronically as technology developed. In recent years, large databases came into existence which supported the storing of these materials. With the continued development of Internet technologies, the document-driven DSS also came into fruition and evolved into an oft-used DSS for organizations [1].

There are many tools that have been developed that are utilized as part of document-driven DSS. Examples are search engines which are linked with document-driven DSS to aid organizations in decision making. The documents for the document-driven DSS are typically not uniform and not standardized in their patterns thus needing an approach to properly retrieve the data and information, and locate the documents from an extensive set of unstructured data groupings. There are good examples of information retrieval systems that are in the market including Infosys and LexisNexis which provide structure to the documents and therefore make the documents much more usable as materials for decision making support in organizations. An alternative that is used in the retrieval of information is the text-based system which is also considered as effective in mining organizational data in identifying the location of documents [22]. Knowledge-driven Decision Support System (DSS)

Another category for DSS is the knowledge-driven DSS which is considered to have started from intelligent decision support systems with a related perspective that these are linked to artificial intelligence [31]. Sander \& Pearson [27] defined knowledge-driven DSS as "a computer-based reasoning system that provides information, comprehension and suggestions to users to support them in decision-making."

The intelligent DSS emanated from the development of two generations:

1. Rule-based knowledge-based systems

2. Fuzzy logic, genetic algorithms, and neural networks [18].

The expert systems that are dependent on rules are largely utilized in processes which relate to scheduling in manufacturing activities. The expert systems are linked to heuristics and could be considered as methods that leads to the appropriate solutions to identified problems. The expert systems also inherently utilize the expert knowledge that are part of the databases in order to properly address the problems in organizations and effectively support decisions made [1].

With further development, the next generation shows increased capability with the integration of elements like fuzzy neural networks, genetic algorithms, and fuzzy logic which can involve linear programing models.

These are utilized to execute unstructured tests with the identification of variables that support the location of the fitness function. The systems which utilize genetic algorithm incorporates genes to result in values which have been revised and which are then used to support decision making processes. The objective in the use of knowledge-driven DSS is to identify specific data and information for knowledge development, and the relevant technologies and methods that can be helpful for the mining of the data. In recent years, organizations have taken actions to automate a larger part of organizational processes. The automation of the processes involves the management of data and information as these are necessary for supporting decision making. DSS requires data and information which have been reviewed and cleaned, and are located in the database. This means that the data has undergone the steps related to data mining and processing, and that the data has been converted to information and thence to knowledge [23].

\section{Web-based DSS}

Another category is web-based DSS and this is viewed as a complex and sophisticated decision support system that has expanded its ability with the utilization of the worldwide web and Internet as part of the processes for supporting decision making. This dprogress in the web-based decision support systems caused a continued technological advancement that has also defined the Internet [10].

\section{DSS Classification based on Scope}

An alternative for the classification of DSS is through the consideration of the scope of use of DSS [17]. From this perspective, the classification for DSS breaks down into two: (i) enterprise-wide DSS; and, (ii) desktop single user DSS.

Enterprise-wide DSS

An enterprise-wide DSS provides support to organizations and decision makers by integrating large databases across different locations in order for the decision makers to have a view over all the data warehouses [17].

Desktop single user DSS 
The desktop single user DSS, in comparison to the enterprise-wide DSS, has a smaller foundation and is typically limited to an individual user's personal computer with this DSS being designed as a point of support for managers [17].

\section{DSS Classification based on Orientation}

Another alternative classification is provided by Holsapple and Whinston[15] and this approach is based on orientation and leads to six categories:

1. Text-oriented DSS

2. Database-oriented DSS

3. Rule-oriented DSS

4. Solver-oriented DSS

5. Spreadsheet-oriented DSS

6. Compound-oriented DSS

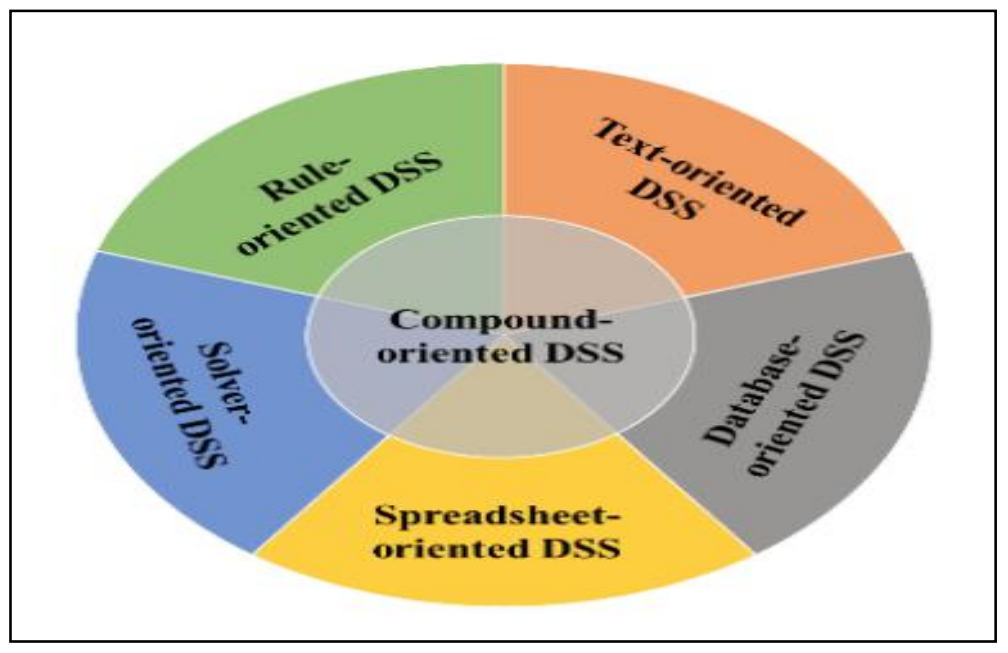

\section{Figure 4: DSS Classification by Orientation (1) (Holsapple\&Whinston 1996)}

A text-oriented DSS aids the decision-making process with the storage of text-based data that can then be accessed, utilized and evaluated by the individual managers and decision makers. The database-oriented DSS involves the storage of data and information across different locations such as in regions which then provides the decision makers access to the data. This gives the decision makers the capacity to get the data and utilize the data and information, even in large amounts of data, to support the decision making process.

The rule-oriented DSS provides a more intelligent approach that incorporates the use of artificial intelligence, which enables the leverage of rules and processes to aid the decision makers in suggested solutions coming from the knowledge base. A solver-oriented DSS could be considered as systems which are specialized as these involve solvers which enable the analysis and development of solutions in various areas subject areas including finance, forecasting and optimization among many others. The spreadsheet-oriented DSS provides decision making support that require the aspects of the development of creating, extracting and improving knowledge. This also allows for the decision makers to establish models that support the analysis of the data and information. The compound DSS is a category of DSS that involves different orientation-based DSS in combination in its application [12].

Another consideration of DSS classification that utilizes orientation was expanded on by Hasan et al [12] with the research by Alter [33] as a basis in the classification of DSS into different categories:

1. File drawer systems

2. Data analysis systems

3. Analysis information systems

4. Accounting models

5. Representational models

6. Optimization models

7. The classification of Alter (1980) was then integrated by Hasan et al [12] into two specific orientations:

A. Data-oriented DSS

B. Model-oriented DSS 


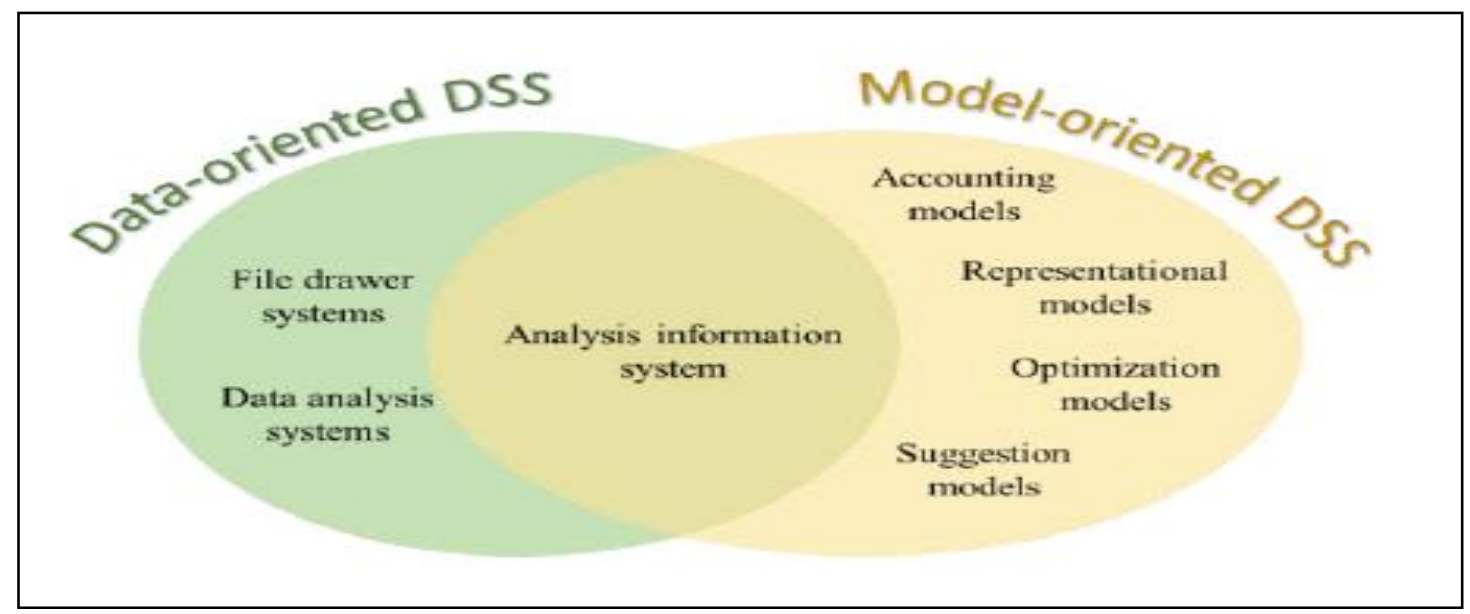

Figure 5: DSS Classification by Orientation (2) (Hasan et al., 2017)

In doing the classification into two specific orientations, the perspectives argued that data analysis systems and file drawer systems form part of data-oriented DSS while accounting models, representational models, and optimization models form part of model-oriented decision support systems. Analysis information system is considered to be part of both model-oriented decision support systems and data-oriented decision support systems thus being located in the intersection of these two DSS orientations [12].

\section{DSS Classification based on Focus Area}

The classification of DSS has evolved further as, in recent years, Hassan et al., [12] recognized associations across the classifications provided by Alter, Power and Holsapple and Whinston, provided a proposal for a possible classification of DSS that was driven by the focus areas of DSS. The argument was that the varied classifications could be consolidated into three major 'focus areas' as the classifications aligned along these areas, which were:

Data focus

Model focus

Knowledge focus

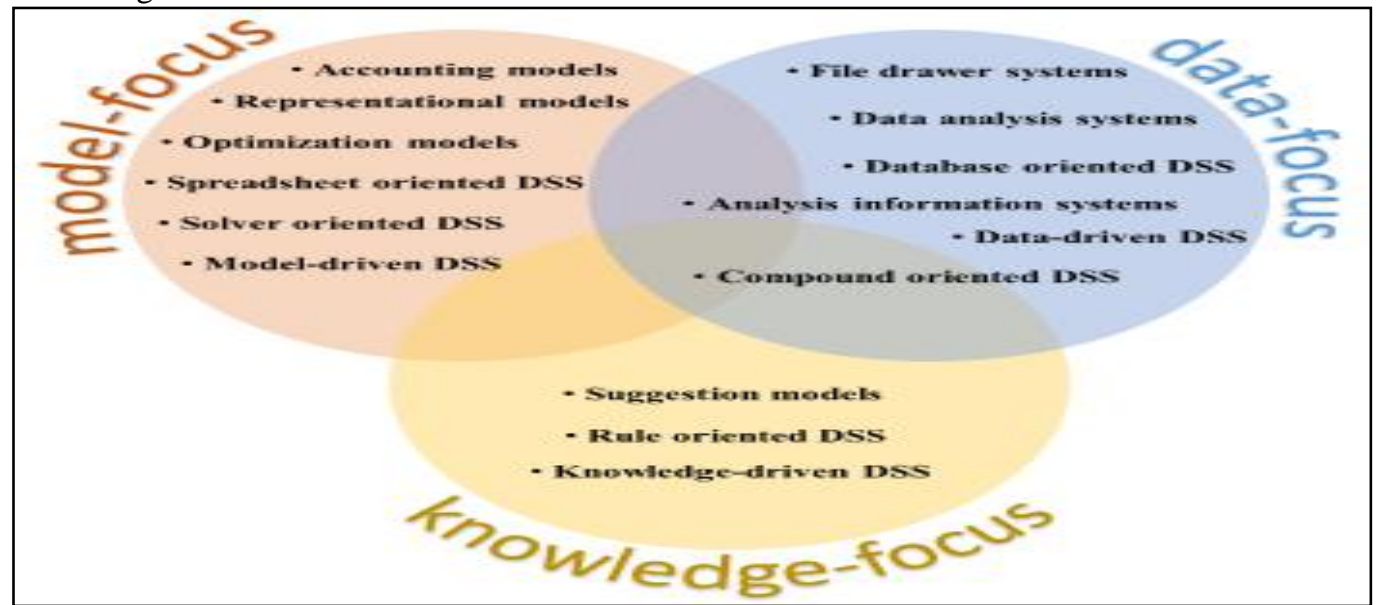

Figure 6: Classifications of DSS by Focus Area (Hasan et al., 2017)

The data focus DSS stems from the reliance on the use of data that can be utilized across large databases in the execution of analysis that would aid the decision making of individuals and managers. The model focus DSS centers on defined systems that leverage the application of models to solve sophisticated problems that require the use of financial models, mathematical applications and optimization models. Finally, knowledge focus DSS are systems that have been refined to include artificial intelligence thereby enabling DSS to replicate human logic in the analysis of problems to recommend solutions for the decision makers [12].

\section{DSS Classification based on Type and Frequency of Decision Making}

Institutional DSS: In using type and frequency of decision making in the classification, one category is institutional DSS which is used in supporting decisions which are recurrent in nature. Institutional DSS in effectively for programmed decisions that are executed on a regular basis such as daily. Several examples provide an understanding of this DSS: process for managing technical problems is established; actions for disciplinary processes; unit manufacturing; and, mechanistic processes as part of troubleshooting methods.

Ad-hoc DSS: Another category based on type and frequency of decision making is the ad-hoc DSS which is applicable in situations where support for decision making is not considered to be regular but in one-off situations. 
In these cases, the solutions identified for a given problem are unique given the one-off nature of the situations. The ad hoc DSS is meant to be used for decisions which are not programmatic, and the likelihood is that the data and information in these situations are incomplete [4].

\section{DSS Classification based on Capacity}

Individual versus Group DSS

For the DSS classification that is based on capacity, the DSS can be either individual or group with the main difference being in the stakeholder supported by the DSS. For individual DSS, this is for an individual while for a group DSS, this is for a group of individuals or a set of executives being supported for their decision making. A group DSS can be a valuable approach in enhancing collaboration and cooperation among managers located in different geographies [16].

\section{DSS Classification based on Objective}

Custom-made vs. vendor-ready-made

The DSS classification can also be based on objective and, in this case, there are two types: custom-made; and, vendorready-made. For a custom-made DSS, this is considered to have a generic system as a starting point with this system then customized for a defined objective [35].

In a custom-made DSS, the key elements for DSS of the database, models, interface and support are already integrated and this enables the system to identify solutions for industry problems that are considered to be regularly-occurring thus reducing costs in the approach [25]. For a vendor-ready-made DSS, these re already designed and configured to address predetermined issues which are usually generic [25].

\section{DSS Classification based on degree of guidance}

\section{Directed and Non-directed DSS}

Classification of DSS can also be through the degree of guidance. A directed DSS presents a targeted DSS with clear guidance provided to a significant extent enabling the issues to be resolved easily. The guidance in this system can be considered to be suggestive only rather than specific [20].

\subsection{DSS Classification based on degree of non-procedurality}

\section{Procedural and Non Procedural DSS}

An alternative approach to DS Classification is through non -procedurality. Bonczek et al., [34] proposed this basis for the DSS classification with the extent of non-procedurality of the retrieval of data and information, and models being provided by the DSS executed. The DSS systems can incorporate advanced features for the retrieval of data and this leads to intermediate levels in the DSS classification based on non-procedurality[4].

Table 1: DSS Types and Classification by Author

\begin{tabular}{|c|c|c|}
\hline Author & Classification Criteria & DSS Type \\
\hline Alter (1980) & Mode of assistance & $\begin{array}{l}\text { File drawer systems } \\
\text { Data analysis systems } \\
\text { Analysis information systems } \\
\text { Accounting models } \\
\text { Representational models } \\
\text { Optimization models }\end{array}$ \\
\hline $\begin{array}{l}\text { Holsapple and Whinston (1996) } \\
\text { Hassan et al (2017) }\end{array}$ & Orientation & $\begin{array}{l}\text { Text-oriented decision support systems } \\
\text { Database-oriented decision support } \\
\text { systems } \\
\text { Rule-oriented decision support systems } \\
\text { Solver-oriented decision support } \\
\text { systems } \\
\text { Spreadsheet-oriented decision support } \\
\text { systems } \\
\text { Compound-oriented decision support } \\
\text { systems } \\
\begin{array}{l}\text { Data-oriented decision support systems } \\
\text { Model-oriented decision support } \\
\text { systems }\end{array}\end{array}$ \\
\hline Haettenschwiler (2001) & User relationship & $\begin{array}{l}\text { Active DSS } \\
\text { Passive DSS } \\
\text { Cooperative DSS }\end{array}$ \\
\hline Power (2004) & Mode of assistance & $\begin{array}{l}\text { Data-driven DSS } \\
\text { Knowledge-driven DSS } \\
\text { Model-driven DSS } \\
\text { Communication-driven DSS }\end{array}$ \\
\hline
\end{tabular}




\begin{tabular}{|c|c|c|}
\hline & & $\begin{array}{l}\text { Document-driven decision support } \\
\text { systems }\end{array}$ \\
\hline Jain (2010) & Scope of use & $\begin{array}{l}\text { Enterprise-wide decision support } \\
\text { systems } \\
\text { Desktop-wide decision support systems }\end{array}$ \\
\hline Hasan et al (2017) & Focus area & $\begin{array}{l}\text { File drawer systems } \\
\text { Data analysis systems } \\
\text { Analysis information systems } \\
\text { Accounting models } \\
\text { Representational models } \\
\text { Optimization models } \\
\text { Text-oriented decision support systems } \\
\text { Database-oriented decision support } \\
\text { systems } \\
\text { Rule-oriented decision support systems } \\
\text { Solver-oriented decision support } \\
\text { systems } \\
\text { Spreadsheet-oriented decision support } \\
\text { systems } \\
\text { Compound-oriented decision support } \\
\text { systems } \\
\text { Data-driven decision support systems } \\
\text { Knowledge-driven decision support } \\
\text { systems } \\
\text { Model-driven decision support systems }\end{array}$ \\
\hline (Cioca et al., 2015) & $\begin{array}{l}\text { Type and Frequency of decision } \\
\text { making }\end{array}$ & $\begin{array}{l}\text { Institutional decision support systems } \\
\text { Ad-hoc decision support systems }\end{array}$ \\
\hline Juneja (2011) & Capacity & $\begin{array}{l}\text { Individual } \\
\text { Group decision support systems }\end{array}$ \\
\hline Rose et al., (2018) & Objective & $\begin{array}{l}\text { Custom } \\
\text { Ready-made DSS }\end{array}$ \\
\hline Noorollahi et al., (2016) & Degree of guidance & $\begin{array}{l}\text { Directed } \\
\text { Non-directed DSS }\end{array}$ \\
\hline Cioca et al., (2015) & Degree of non-procedurality & $\begin{array}{l}\text { Procedural } \\
\text { Non-procedural DSS }\end{array}$ \\
\hline
\end{tabular}

\section{Current Trends and Further Work}

Recent studies have tended towards enhancing decisions to be intelligent decisions with these being integrated in businesses. There is significant advancement in artificial intelligence and this is complemented by big data developments. Together, these provide for new paths for further research in DSS with decision making being evolved into an approach that is increasingly more evidential and significantly objective in the underlying basis [3].

A considerable implication of the development of artificial intelligence systems is the enhancement of the data analysis approaches. Brendel et al., [3] argue that factors such as the collection of data, its utilization and its storage in databases do not have any impact on decision making by individuals and managers.

Instead, other data elements including volume (a significant amount of data generated), velocity (an effective approach to regularly developing, securing and storing real-time data), variety (a mixed set of data and information reflecting different types and sources including structured and unstructured), veracity (a consideration of the existence of inconsistent data), value (a process in which data is integrated into business processes and overall environment), validity (an assurance that data is effectively evaluated and aligned with defined standards) which are dimensions for big data have larger implications in decision making. The effectiveness of the decision-making process is assessed through the extent of fulfillment of the characteristic Vs defined earlier to support a set of properly defined and analyzed data [9].

In relation to DSS applications that are reviewed in this research, there is considerable possibility for research on DSS to benefit from enhancements in Human Computer Interaction (HCI), artificial intelligence and the considerably large databases that are formed from the set of data and information in organizations. Data-driven DSS can be utilized to access a larger and enhanced database real time. The model-driven DSS could be considered as having an evolution that is more practical and more detailed. The communication-based DSS presents an approach that relies more on improved visual communication support which, in turn, enables an improved and deeper study on decision support where collaboration can be leveraged to lead to knowledge discovery.

\section{Conclusion}


This research presented a review of literature of studies on Decision Support Systems. The review presented an extensive set of potential applications for DSS. This research provided a summary of the DSS classification based on varying criteria (user relationship, orientation, scope of use, mode of assistance, and focus area) that different authors had perspectives on. The classifications are presented in Table 1.

While data-driven DSS requires a significant volume of properly defined and structured data with the capabilities to management internal and external organizational data in real time, model-driven DSS does not require extensive data. In addition, model-driven DSS allows for the manipulation of model parameters by the user with the DSS providing support to decision makers. Furthermore, document-driven DSS can aid in the structuring of documents to have improved support for decision making.

Knowledge-driven DSS requires machine-based systems that are exclusive. This results from the inclusion of technologies helping develop artificial intelligence, expert systems and data mining. Finally, communication-driven DSS is deemed to significantly rely on the integration of network and e-communication technologies to enhance collaboration between key decision makers and to create a situation that allows team work, cooperation and communication between the key decision makers of the team.

\section{$\underline{\text { References }}$}

[1]Agrawal, V., Panigrahi, B. K., \&Subbarao, P. M. V. (2017). Intelligent decision support system for detection and root cause analysis of faults in coal mills. IEEE Transactions on Fuzzy Systems, 25(4), 934-944.

[2]Arnott, D., \&Pervan, G. (2016). A critical analysis of decision support systems research revisited: the rise of design science. In Enacting Research Methods in Information Systems (pp. 43-103). Palgrave Macmillan, Cham.

[3]Brendel, A. B., Brennecke, J. T., Zapadka, P., \& Kolbe, L. M. (2017). A Decision Support System for Computation of Carsharing Pricing Areas and its Influence on Vehicle Distribution.

[ 4]Cioca, M., \& Filip, F. (2015). Decision Support Systems -A Bibliography 1947-2007. Database, 15(4), 10-14.

[5]Dasgupta, D., \& Gonzalez, F. A. (2001, May). An intelligent decision support system for intrusion detection and response. In International Workshop on Mathematical Methods, Models, and Architectures for Network Security (pp. 114). Springer, Berlin, Heidelberg.

[6]Dweiri, F., Kumar, S., Khan, S. A., \& Jain, V. (2016). Designing an integrated AHP based decision support system for supplier selection in automotive industry. Expert Systems with Applications, 62, 273-283.

[7]Felsberger, A., Oberegger, B., \& Reiner, G. (2016, October). A Review of Decision Support Systems for Manufacturing Systems. In SAMI@ iKNOW.

[8]Fielder, A., Panaousis, E., Malacaria, P., Hankin, C., \&Smeraldi, F. (2016). Decision support approaches for cyber security investment. Decision Support Systems, 86, 13-23.

[9]Garg, H. (2017). A Novel Improved Accuracy Function for Interval Valued Pythagorean Fuzzy Sets and Its Applications in the Decision- Making Process. International Journal of Intelligent Systems, 32(12), 1247-1260.

[10 ]]Ginzberg, M. J., \&Stohr, E. A. (1982). Decision support systems: issues and perspectives.

[11]Haettenschwiler, P. (2001). Neuesanwenderfreundlicheskonzept der entscheidungsunterstützung. Zurich, vdfHochschulverlag AG, 189-208.

[12]Hasan, M. S., Ebrahim, Z., Mahmood, W. H. W., \& Ab Rahman, M. N. (2017). Decision support system classification and its application in manufacturing sector: A review. JurnalTeknologi, 79(1), 153-163.

[13]Hermann, Pentek, Otto, 2016: Design Principles for Industrie 4.0 Scenarios, accessed on 4 May 2016

[14]Hogenboom, F., Frasincar, F., Kaymak, U., De Jong, F., \& Caron, E. (2016). A survey of event extraction methods from text for decision support systems. Decision Support Systems, 85, 12-22.

[15]Holsapple, C. W. 2008. DSS Architecture and Types. Handbook on Decision Support Systems 1: Basic Themes, F. Burstein and C. W. Holsapple, Eds. Springer Berlin Heidelberg. 163-189.

[16]Hu Juneja, J. (2011). FirstHimanshu, and PrachiJuneja.". Management." Management Study Guide. WebCraftPvt Ltd.

[17]Jain, S. (2010). Decision Support Systems. Presentation.

[18]Liu, S., Delibasic, B., Butel, L., \& Han, X. (2017). Sustainable knowledge-based decision support systems (DSS): perspectives, new challenges and recent advance. Industrial Management \& Data Systems, 117(7), 1318-1322.

[19]Masum, A. K., Beh, L. S., Azad, A. K., \&Hoque, K. (2018). Intelligent Human Resource Information System (iHRIS): A Holistic Decision Support Framework for HR Excellence. INTERNATIONAL ARAB JOURNAL OF INFORMATION TECHNOLOGY, 15(1), 121-130.

[20] Noorollahi, Y., Yousefi, H., \&Mohammadi, M. (2016). Multi-criteria decision support system for wind farm site selection using GIS. Sustainable Energy Technologies and Assessments, 13, 38-50.

[21]Power, D. (2004). DSS?. DSS News, 5(19).

[22]Power, D. J., \&Heavin, C. (2017). Decision support, analytics, and business intelligence. Business Expert Press.

[23]Rodela, R., Bregt, A. K., Ligtenberg, A., Pérez-Soba, M., \&Verweij, P. (2017). The social side of spatial decision support systems: Investigating knowledge integration and learning. Environmental Science \& Policy, 76, 177-184. 
[24]Romiszowski, A. J. (2016). Designing instructional systems: Decision making in course planning and curriculum design. Routledge.

[25] Rose, D. C., \& Bruce, T. J. (2018). Finding the right connection: what makes a successful decision support system? Food and Energy Security, 7(1), e00123.

[26]Samuel, O. W., Asogbon, G. M., Sangaiah, A. K., Fang, P., \& Li, G. (2017). An integrated decision support system based on ANN and Fuzzy_AHP for heart failure risk prediction. Expert Systems with Applications, 68, 163-172.

[27]Sander, T., \& Pearson, S. (2018). Decision support for selection of cloud service providers. GSTF Journal on Computing (JoC), l(1).

[28]Torregrossa, D., Hernández-Sancho, F., Hansen, J., Cornelissen, A., Popov, T., \& Schutz, G. (2017). Energy saving inwastewater treatment plants: A plant-generic cooperative decision support system. Journal of Cleaner Production, 167, 601-609.

[29]Trianni, A., Cagno, E., \&Farné, S. (2016). Barriers, drivers and decision-making process for industrial energy efficiency: A broad study among manufacturing small and medium-sized enterprises. Applied Energy, 162, 1537-1551.

[30]Turban, E., J. E. Aronson, and T.-P. Liang. 2005. Decision Support Systems and Intelligent Systems. 7th ed. Pearson Prentice Hall.

[31]Yang, G., Liu, L., Guo, P., \& Li, M. (2017). A flexible decision support system for irrigation scheduling in an irrigation district in China. Agricultural water management, 179, 378-389.

[32]Zulkafli, Z., Perez, K., Vitolo, C., Buytaert, W., Karpouzoglou, T., Dewulf, A., \& Shaheed, S. (2017). User-driven design of decision support systems for polycentric environmental resources management. Environmental Modelling \& Software, 88, 58-73.

[33] Steven Alter, (1980) Decision support systems: Current practice and continuing challenges", Addison-Wesley publication.

[34] Robert Bonczek, (1980), The evolving roles of models in decision support systems, Decision Sciences Journal.

[35] Cristian Barz, Claudious Klaua, Jalba, Zoltan Erdei, Sarah Myriam Lydia Hahn, (2019) Approaches for the planning and implementation of industry 4.0, , Periodical of Engineering and Natural Sciences, Vol. 7, No. 1. 